\title{
Três críticos latino-americanos
}

LUIZ JACKSON"

ALEJANDRO BLANCO"

\section{Resumo}

A avaliação dos papéis desempenhados pelos críticos literários na formação do campo intelectual mexicano, em contraposição ao Brasil e à Argentina, além do grau e das modalidades de institucionalização (universidade, imprensa, revistas etc.) dessa atividade em torno da década de 1950 é o objetivo central deste artigo. Nessa direção, propomos tomar como ponto de partida a trajetória e a produção intelectual do reconhecido crítico e historiador da literatura mexicana, José Luis Martínez (1918-2007), visando compará-las com as do brasileiro Antonio Candido (1918-2017) e do argentino Adolfo Prieto (1928-2016). Praticada até meados do século XX de forma mundana e entendida como um gênero menor da literatura, a crítica seria alavancada por sua institucionalização universitária, mais precisamente pela criação de cursos superiores em letras, ocorrida nos três países na primeira metade desse século, que, progressivamente, conferiu aos críticos meios específicos de legitimação e, cada vez mais, independentes da chancela dos escritores. Obviamente tal processo se deu lentamente e de maneira conflituosa, mas a ascensão e a autoridade conquistada por esses novos produtores culturais alteraram a morfologia e as relações de força nos campos literário e acadêmico.

Palavras-chave: Críticos literários. Trajetórias. Campo literário. Universidade. América Latina.

\footnotetext{
"Universidade de São Paulo, Brasil.

** Universidad Nacional de Quilmes, Argentina.

- Este artigo contou com financiamento da Fapesp, na modalidade auxílio regular à pesquisa. Agradecemos à instituição por viabilizar a pesquisa e ao parecerista do projeto pelas sugestões.
} 


\section{Three Latin American critics}

\section{Abstract}

The main purpose of this article is to evaluate the roles played by literary critics in the formation of Mexican intellectual field, in comparison to Brazil and Argentina, as well as the degree and modalities of institutionalization (university, press, magazines, etc.) of this activity in the 1950s. Thus, we start by analyzing the trajectory and the intellectual production of the recognized critic and historian of Mexican literature, José Luis Martínez (1918-2007), in order to compare them with those of the Brazilian critic, Antonio Candido (1918-2017), and the Argentinian, Adolfo Prieto (1928-2016). Literary criticism, whose practice until the middle of the twentieth century was mundane and understood as a minor genre of literature, came to be leveraged by its institutionalization in the universities, more precisely by the creation of graduate courses, which occurred in the three countries in the first half of that century, which progressively, gave the critics specific means of legitimation and, increasingly, independent of the stamp of writers. Obviously this process occurred slowly and in a conflictive way, but the rise and authority gained by these new cultural producers altered the morphology and relations of force in the literary and academic fields.

Keywords: Literary criticism. Trajectories. Literary field. University. Latin America.

\section{Introdução}

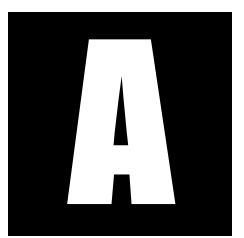

avaliação dos papéis desempenhados pelos críticos literários na formação do campo intelectual mexicano, em contraposição ao Brasil e à Argentina, além do grau e das modalidades de institucionalização (universidade, imprensa, revistas, etc.) dessa atividade em torno da década de 1950 é o objetivo central deste artigo. Nessa direção, propomos tomar como ponto de partida a trajetória e a produção intelectual do reconhecido crítico e historiador da literatura mexicana, José Luis Martínez (1918-2007), visando compará-las com as do brasileiro Antonio Candido (1918-2017) e do argentino Adolfo Prieto (1928-2016), já estudadas anteriormente (Jackson; Blanco, 2014). 
A emergência desses e de outros críticos especializados (e de outros produtores intelectuais, como filósofos, historiadores, antropólogos e sociólogos) na América Latina se fez possível no interior de processos de diferenciação da atividade intelectual, que em cada país teve ritmo e feição distinta, mas que, de modo geral, ganharam força em torno de 1950, associados ao crescimento das universidades. Tais processos foram condicionados pelas mudanças ocorridas nas dimensões mais amplas da sociedade, da economia e da política, aceleradas a partir de 1930. A urbanização e a metropolização de cidades como São Paulo, Buenos Aires e Cidade do México implicou uma alteração no equilíbrio entre mundo rural e urbano, o notável crescimento da população citadina e o surgimento de novas fórmulas políticas que canalizaram as demandas dos grupos emergentes ${ }^{1}$.

Tais cidades constituíram-se desde o início do século XX como "metrópoles culturais". ${ }^{2}$ Sobre a constituição das mesmas como locus dos empreendimentos culturais e científicos, deve-se notar o alto grau de centralização (tomando os países como referência) em Buenos Aires e na Cidade do México. São Paulo nunca monopolizou tais empreendimentos, divididos (ou disputados) com o Rio de Janeiro e, em menor grau, com Recife, Salvador, Belo Horizonte, Porto Alegre etc. ${ }^{3}$ Quanto à composição dos mercados de bens culturais (imprensa, editoras, revistas, museus, teatros) existentes em tais cidades, o de Buenos Aires foi (predominante-

\footnotetext{
${ }^{1}$ Deve-se notar que as duas primeiras cidades haviam sido transformadas radicalmente entre o final do século XIX e o começo do século XX pelo impacto da imigração europeia (principalmente italianos e espanhóis), que implicou o incremento da mobilidade social (sobretudo em Buenos Aires) e a constituição de estratos médios urbanos, principais beneficiados pela expansão do sistema educacional, em especial. A partir da década de 1930, as três cidades sofreram novas alterações demográficas provocadas pelas migrações internas, associadas à industrialização.

${ }^{2}$ Sobre São Paulo, ver Arruda (2001); Buenos Aires, Sarlo (1988); Cidade do México, Kandell (1990).

${ }^{3}$ A respeito dos graus de centralização dos sistemas culturais, vale lembrar o argumento de Lewis Coser que associa a centralização à maior integração das comunidades intelectuais e à propensão à circulação de ideias, modas etc. (Coser, 1967).
} 
mente) privado, o da Cidade do México (predominantemente) público, e misto o de São Paulo.

Essas mudanças afetaram o sistema universitário, cuja população praticamente dobrou nos três países ${ }^{4}$ durante a década de 1950, alterando a hierarquia e as relações de força entre as diversas unidades componentes (universidades, faculdades e disciplinas). Principalmente no Brasil e na Argentina, tal mudança afetou também a composição social do alunato, incorporando mulheres, filhos de imigrantes e judeus. No caso do México, caso privilegiado neste artigo, tais transformações tiveram como eixo a Revolução Mexicana e o reordenamento do sistema de produção cultural dela derivado, cujo traço mais específico seria o da sobredeterminação política, relacionada à debilidade do mercado cultural privado.

Nas três experiências, de modo geral, os críticos travaram relações de disputa (mas também de aliança) com os escritores pela arbitragem do campo literário, estribadas, em maior ou menor medida, na reivindicação da crítica literária como ciência ou como saber especializado 5 . Praticada até meados do século XX de forma mundana e entendida como um gênero menor da literatura, a crítica seria alavancada por sua institucionalização universitária, mais precisamente pela criação de cursos superiores em letras, ocorrida nos três países na primeira metade desse século, que, progressivamente, conferiu aos críticos meios específicos de legitimação e, cada vez mais, independentes da chancela dos escritores. Obviamente tal processo se deu lentamente e de maneira conflituosa, mas a ascensão e a autoridade conquistada por esses

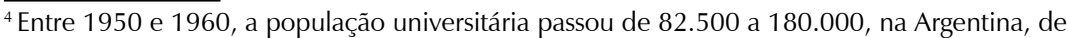
51.000 a 95.700, no Brasil e de 35.200 a 77.000, no México.

${ }^{5}$ Essas relações ambivalentes de aliança e disputa entre críticos e escritores não são exclusivas dessas três experiências, mas características estruturais de campos literários relativamente autonomizados. De acordo com Bourdieu (1996), os críticos alinham-se aos escritores ao participarem diretamente da produção da crença e do valor literário e haveria homologia entre as diferentes posições reivindicadas pelos escritores e críticos, mas estes se contrapõem àqueles ao reivindicarem a exclusividade do papel de árbitros da produção literária. Cada juízo sobre uma obra ou autor seria desse modo um reclamo pela legitimidade da crítica literária como atividade especializada.
} 
novos produtores culturais alteraram a morfologia e as relações de força nos campos literário e acadêmico (Jackson; Blanco, 2014).

A escolha dessas três experiências nacionais se justifica pela escala dos fenômenos comparados. Os críticos literários especializados se projetaram no interior de grandes universidades públicas sediadas em metrópoles culturais, como foram a Universidade Nacional Autônoma do México, a Universidade de Buenos Aires e a Universidade de São Paulo. Nessas três, a criação de novos cursos, no interior das humanidades, especialmente os de letras, engendrou padrões renovados de produção intelectual, derivados, também, do impacto das diferentes missões estrangeiras que atuaram no México, no Brasil e na Argentina. Os agentes foram selecionados em função de algumas propriedades comuns de suas trajetórias: os três tiveram formação acadêmica, foram professores universitários e seus projetos intelectuais, muito reconhecidos, tiveram como eixo a reconstrução da história literária de seus países.

Nessa direção, a reconstrução da carreira intelectual de José Luis Martínez permite apreender esse processo e sua especificidade no México. Ele foi quem mais se aproximou do perfil do crítico literário universitário na Faculdade de Filosofia e Letras da UNAM, nas décadas de 1940 e 1950 e sua obra como crítico e historiador da literatura mexicana, sobretudo, o conjunto de livros e textos que produziu nesse período, justamente quando esteve diretamente ligado a essa universidade, estabeleceu as bases da crítica literária especializada, ao propor métodos e conceitos para a análise do fato literário e um sistema de classificação e ordenamento da literatura mexicana.

Este artigo divide-se em três partes. Nas duas primeiras, analisamos a trajetória social e o projeto intelectual de José Luis Martínez e na terceira ensaiamos uma comparação com as de Antonio Candido no Brasil e Adolfo Prieto na Argentina, visando compreender as semelhanças e as diferenças 
entre os casos analisados. Para tanto, mobilizaremos como parâmetros principais para a comparação as relações entre intelectuais e Estado, as formas de organização das instituições universitárias, as origens sociais dos críticos, as relações com os escritores e os estilos das obras produzidas.

\section{Esboço de trajetória}

Filho de Juan Martínez Reynaga (1888-1962), um médico remediado, José Luis Martínez nasceu em Atojac, no estado de Jalisco, no ano de 1918, como filho primogênito do primeiro casamento de seu pai, enviuvado cedo e casado em segundas núpcias com Lucía Rodríguez, irmã de sua primeira esposa Julia Rodríguez. A prole de dez crianças formou-se com quatro do primeiro casamento e seis do segundo ${ }^{6}$. Recebeu educação privilegiada, seus primeiros estudos foram na cidade de Zapotlan, onde viveu entre 1924 e 1930, no Colegio Renacimiento, no qual o futuro escritor Juan José Arreola foi seu colega. Estudou por um ano (1931), ainda, no Colegio Francés La Salle de México na Cidade do México, antes de ingressar em 1932 na Secundaria, cursada na Universidade de Guadalajara, como a Preparatoria, concluída em 1937. Nesse mesmo ano migrou para a Cidade do México, cumprindo um padrão recorrente dos aspirantes provincianos à formação universitária, mesmo entre aqueles oriundos de estados fortes como Jalisco. Uma vez estabelecido na capital, com vinte anos de idade, ingressou na Faculdade de Medicina da UNAM, curso do qual desistiria depois de dois anos, rompendo assim com a expectativa paterna. Paralelamente, cursou também Letras Espanholas na Faculdade de Filosofia e Letras da UNAM, ao qual se dedicaria mais intensamente, mas igualmente sem diplomar-se ${ }^{7}$. Assim mesmo, entre o

\footnotetext{
${ }^{6}$ Fonte: entrevista dos autores com Rodrigo Martínez Baracs em julho de 2017.

${ }^{7}$ A recusa da herança paterna (medicina/polo masculino) e a identificação com a mãe e a babá (letras/polo feminino) condicionou, possivelmente, esse movimento de reorientação "vocacional".
} 
final da década de 1930 e meados da década de 1950 esteve ligado à universidade, primeiro como aluno, depois como professor $^{8}$, realizando mesmo que não exclusivamente no período uma aposta considerável na carreira universitária.

A universidade havia sido criada em 1910, nos últimos momentos do regime de Porfirio Díaz, mas seu funcionamento inicial foi dificultado em função da instabilidade política provocada pela revolução. A designação como Universidade Nacional Autônoma do México ocorreu no ano de 1929, mas a polarização entre os que entendiam a universidade como instituição subordinada ao Estado e os que reivindicavam sua autonomia permaneceria como fundamento dos conflitos que se prolongariam até o final da década de 1930 (Lempérière, 1992; Garciadiego, 1996). Justamente nesse momento, durante o governo de Lázaro Cárdenas e seguintes, ocorreu a criação de um conjunto de instituições de ensino, pesquisa e difusão, que constituíram a base do sistema científico e cultural do país na segunda metade do século XX: Escola Nacional de Economia (1934), Instituto Nacional Politécnico (1937), Escola Nacional de Antropologia e História (1938), Colégio do México (1939), Instituto Indigenista Interamericano (1940), Instituto Nacional de Belas Artes (1946), Instituto Nacional Indigenista (1948), Editora Fondo de Cultura Económica (1934), as academias Seminário de Cultura Mexicana (1942) e Colégio Nacional (1943), além dos prêmios nacionais em Artes, Ciências e Letras (1945). A inauguração da Cidade Universitária, no começo da década de 1950, coroaria esse processo de investimentos públicos que viriam a constituir a base concreta do sistema cultural e universitário, relativamente integrado em função de sua dependência (em graus distintos) ao Estado. Devemos recordar que o Estado mexicano centralizou, mais do que na Argentina e 
no Brasil, a produção cultural, compensando a extrema debilidade de seu mercado privado de bens culturais, que já era forte na Argentina e, ainda que em menor medida, também, no Brasil, nas décadas de 1930 e 1940.

A Faculdade de Filosofia e Letras foi criada em 1924 a partir da subdivisão da Escola Nacional de Altos Estudos, esta inaugurada em 1910, mas seu impulso mais consistente se daria desde o final dos anos de 1930, condicionado pela incorporação de professores espanhóis exilados ao seu quadro docente. É justamente nesse momento que o jovem José Luis Martínez ingressa na instituição ${ }^{9}$. Seu primeiro lance, ainda como estudante, foi a iniciativa editorial conjunta com Alí Chumacero, Jorge González Durán e Leopoldo Zea ao idealizaram a revista Tierra Nueva (1940-1942), que os introduziu nos círculos literários mais prestigiosos, como os de Alfonso Reyes ${ }^{10}$ e Octavio Paz ${ }^{11}$. Martínez, Chumacero e González Durán nasceram em 1918 no mesmo estado, Jalisco, e se conheceram muito jovens. Os dois primeiros estudaram juntos desde a secundária e formaram com González Duran um trio de amigos muito próximos na Escuela Preparatoria de Guadalajara. Zea, a quem conheceram na universidade, foi o último a ingressar na empreitada, viabilizada pela Imprenta Universitaria, graças ao apoio que conseguiram do secretário geral da UNAM Mario de

\footnotetext{
${ }^{8}$ Tornar-se professor sem concluir a graduação foi possível no contexto inicial de institucionalização universitária, quando os direitos de ingresso ao ensino universitário eram ainda pouco formalizados. ${ }^{9}$ Em entrevistas, Martínez destacou a importância de tal circunstância em sua formação, nomeando especialmente os professores espanhóis José Gaos e Enrique Díez-Canedo, além dos mexicanos Julio Torri, Julio Jiménez Rueda, Francisco Monterde e Manuel Toussaint.

${ }^{10}$ Segundo depoimentos (Carballo, 1989; Martínez, 1990; Valero; Herrera, 2005), os jovens mentores da revista procuraram Alfonso Reyes, a quem não conheciam pessoalmente, para pedir-lhe o título da revista. O episódio revela a importância estratégica do patrocínio intelectual como mecanismo de ingresso à vida literária. $\mathrm{O}$ fenômeno do patrocínio intelectual no México foi discutido por Roderic Camp em diversos trabalhos (1981; 1983).

${ }^{11}$ Vale citar trecho de entrevista concedida a Marco Antonio Campos: "Gracias a Tierra Nueva conocimos a los de la generación siguiente a Contemporáneos, es decir, el grupo de Taller, conocí a Octavio Paz a quién veía después en las tertulias del Café París." (Garrido, 1990, p. 82)
} 
la Cueva. Para todos eles, a revista foi uma plataforma de lançamento, de Chumacero e González Durán como poetas, Zea como filósofo e Martínez como crítico literário. A revista definiu também a orientação intelectual mais geral assumida pelo grupo, como o próprio Martínez afirmou reflexivamente em um de seus principais textos ${ }^{12}$.

Curiosamente, o primeiro texto de Martínez em Tierra Nueva foi o poema Elegia por Melibea, o único que publicaria, que possivelmente se refere à perda de sua mãe, ocorrida em sua infância. O poema pode ser entendido, também, como uma despedida de suas pretensões literárias, antes de sua afirmação como crítico e historiador da literatura. Nessa direção, a revista foi para ele um divisor de águas. ${ }^{13}$

O grupo de Tierra Nueva (embora seu núcleo tenha origem em Guadalajara) e a revista se fizeram a partir da experiência vivida na Faculdade de Filosofia e Letras da UNAM, sob a influência direta dos professores espanhóis exilados (VVAA, 1982; VVAA, 1999; Zabludovsky, 2002), como José Gaos (e outros), que moldaram neles hábitos mais sistemáticos de estudo. Além disso, como vimos, o suporte material provinha diretamente da universidade e fazia da revista uma publicação chancelada diretamen-

\footnotetext{
${ }^{12}$ Vale citar o trecho do texto "Panorama de la literatura contemporánea", no qual, sete anos depois do fim da revista, avaliou a orientação do grupo (e de si mesmo): "El grupo que se dio a conocer en la revista bautizada por Alfonso Reyes como Tierra Nueva (1940-1942) tuvo, entre sus designios más conscientes, el de buscar un equilibrio entre la tradición y la modernidad, entre el entusiasmo iconoclasta de la juventud y la aceptación de un rigor en la formación literaria. Su reconocimiento de algunos maestros en las generaciones mayores, su aspiración a realizar una obra con la austeridad que requiere un oficio que se aprende fatigosamente y su preocupación por ir conquistando, sin prisa pero sin descanso, el mundo de la cultura, les confirieron, cuando menos, sólidas bases de las que podían partir bien dirigidos. Pudiera decirse de su actitud, que trata de aprovechar las inquietudes más válidas de las generaciones más inmediatas, evitando sus riesgos y abdicaciones (Martínez, [1949] 1990, p. 91). Sobre Tierra Nueva, ver Garganigo (1965) e Valero e Herrera (2005).

${ }^{13}$ Ainda na década de 1940, o crítico colaborou assiduamente em duas revistas literárias importantes, dirigidas por Octavio Barreda (1896-1964), Letras de México (1937-1947) e El Hijo Pródigo (1943-1946). Escreveu, também, nos principais jornais de então, El Nacional, Excélsior e Novedades (Martínez Baracs, 2017).
} 
te por essa instituição. Deve-se notar que esse era um padrão tipicamente mexicano, em função da força que detinha o setor público na produção cultural, diferentemente do Brasil e da Argentina, países nos quais as iniciativas privadas tiveram maior importância relativa na composição do mercado cultural ${ }^{14}$ em meados do século XX. Por outro lado, ambos (a revista e o grupo) se legitimaram simultaneamente no espaço contíguo dos escritores, pelo patrocínio intelectual de Alfonso Reyes. Nesse sentido, essa empresa intelectual articulava a cultura literária estabelecida à cultura universitária emergente, numa configuração específica que se ordenava menos pela oposição e mais pela integração entre as mesmas. Tal integração tinha como base o alto grau de homogeneidade social entre os diferentes grupos intelectuais no México, dada pela origem social favorável e urbana, pela formação educacional compartilhada (Escola Nacional Preparatória/UNAM) ${ }^{15}$, pelo dinamismo dos circuitos mundanos de sociabilidade (cafés, bares, cantinas, museus, etc.) e pelo padrão recorrente das carreiras ocupacionais dos escritores e dos universitários, fortemente atreladas ao Estado, que os cooptava por meio de cargos burocráticos, políticos e diplomáticos (Camp, 1981; 1983).

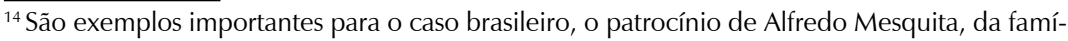
lia proprietária do jornal O Estado de São Paulo, em diversas iniciativas culturais, como a da revista Clima, também editada por jovens estudantes da Faculdade de Filosofia, Ciências e Letras da Universidade de São Paulo na década de 1940, entre os quais figuravam Antonio Candido, Décio de Almeida Prado e Paulo Emílio Salles Gomes. No caso argentino, a emblemática revista Sur foi diretamente custeada por sua mentora Victoria Ocampo e Contorno, também editada por estudantes da Faculdade de Filosofia e Letras da Universidade de Buenos Aires na década de 1950, se manteve graças a recursos privados de seus editores, especialmente os irmãos Viñas.

${ }^{15}$ É preciso sublinhar esse dado de que já no começo do século XX a grande maioria dos escritores mexicanos eram diplomados, em contraponto à Argentina, onde muitos escritores eram autodidatas, ou melhor, educados no próprio ambiente familiar. No México, portanto, essa propriedade social compartilhada, a posse do diploma obtida nas mesmas instituições, aproximava escritores e críticos universitários.
} 
Nesse sentido, Tierra Nueva não foi para José Luis Martínez apenas uma plataforma de ingresso no mundo intelectual; a revista favoreceu, também, seu ingresso no serviço público, ao qual acedeu como "Secretário Particular do Secretário de Educação Pública"16 (1943-1946), servindo ao escritor Jaime Torres Bodet, que fora seu professor na FFyL/UNAM. O padrão de dependência dos intelectuais ao Estado no México até pelo menos a década de 1970, que premiava o sucesso intelectual com cargos públicos de prestígio, explica a correlação que se pode observar entre a progressão da carreira intelectual de José Luis Martínez e a da carreira no serviço público, de modo que sua consagração como crítico e historiador da literatura, paradoxalmente, o distanciaria dessa última atividade, ao menos do ponto de vista da carreira universitária, na qual ele esteve envolvido até a metade da década de 1950 e na qual poderia ter prosseguido se a estrutura de possibilidades fosse outra, como veremos ao comparar sua trajetória com as de Adolfo Prieto na Argentina e de Antonio Candido no Brasil. Vejamos a sequência de suas ocupações principais no serviço público e na universidade (como professor e pesquisador) entre as décadas de 1940 e 1970 no quadro abaixo:

\begin{tabular}{|c|c|c|c|c|c|}
\hline $\begin{array}{l}\text { Décadas / } \\
\text { Ocupações }\end{array}$ & 1940 & 1950 & 1960 & 1970 & 1980 \\
\hline Universidade & $\begin{array}{l}\text { Ensino/ } \\
\text { Pesquisa }\end{array}$ & $\begin{array}{l}\text { Ensino/ } \\
\text { Pesquisa }\end{array}$ & & & \\
\hline $\begin{array}{l}\text { Serviço } \\
\text { Público }\end{array}$ & $\begin{array}{c}\text { Cargos } \\
\text { burocráticos }\end{array}$ & $\begin{array}{l}\text { Cargos } \\
\text { burocráticos } \\
\text { e políticos }\end{array}$ & $\begin{array}{c}\text { Cargos } \\
\text { diplomáticos } \\
\text { e burocráticos }\end{array}$ & $\begin{array}{c}\text { Cargos } \\
\text { diplomáticos } \\
\text { e burocráticos }\end{array}$ & $\begin{array}{l}\text { Cargos } \\
\text { burocráticos } \\
\text { e políticos }\end{array}$ \\
\hline
\end{tabular}

\footnotetext{
${ }^{16}$ No México, o cargo de secretário de educação pública corresponde ao de ministro de educação no Brasil e na Argentina.
} 
O quadro indica a sobreposição entre suas atividades no serviço público e na universidade, entre 1940 e 1960. No serviço público, Martínez foi secretário particular de Jaime Torres Bodet, Secretario de Educación Pública, entre 1943 y 1946; Secretário Administrador do Colegio Nacional entre 1947 e 1952; secretário particular de Roberto Amorós (Gerente de Ferrocarriles Nacionales de México) em 1952 e 1953, e Ajudante Gerente Geral de Relações Públicas e Serviços Sociais de Ferrocarriles Nacionales, até 1958; Conselheiro da "Productora e Importadora de Papel, S. A." (PIPSA) de 1956 a $196{ }^{17}$. Como professor universitário, José Luis Martínez lecionou literatura mexicana na ENP da UNAM entre 1940 e 1943 e entre 1947 e 1950. Foi professor de espanhol na Escola de Verão da UNAM entre 1942 e 1944, na Escola Normal Superior entre 1945 e 1951 e na Universidade Feminina entre 1946 e 1949. Na FFyL da UNAM, ofereceu o curso de Crítica Literária e Literatura Mexicana do Século XIX entre 1949 e $1952^{18}$ e 1959 e 1960. No Colégio do México, colaborou com Raimundo Lida no Centro de Estudos Filológicos e Literários, no qual também lecionou. Depois de 1960, afastou-se da universidade e dedicou-se à carreira pública e secundariamente ao trabalho intelectual. Podemos tomar como marco dessa viragem, sua designação como embaixador do México em Lima (1961-1962). Em seguida seria embaixador na UNESCO, em Paris (1963-1964), e diretor do Instituto Nacional de Bellas Artes (1965-1970). Seria novamente embaixador, na Grécia, entre 1971 e 1974, e diretor da editora Fondo de Cultura Económica, entre 1976 e 1982. Devemos atentar, também, à sua militância política mais direta no partido dominante, o PRI, também decisiva à progressão de sua carreira

\footnotetext{
${ }^{17}$ Fontes: Currículo de José Luis Martínez e Martínez Baracs (2017).

${ }^{18}$ Cabe citar: "Las páginas coleccionadas ahora fueron escritas a lo largo de seis años, de 1947 a 1952, consagrados casi totalmente al estudio del siglo XIX, años que coincidieron, además, con una cátedra sobre la materia, en la Facultad de Filosofía y Letras de la Universidad [Nacional] de México. De aquellas horas de estudio y de esta cátedra en la que tuve los alumnos más cordiales -entre ellos algunos a los que pude transmitir mi amor por nuestro siglo XIX-, conservo un recuerdo nostálgico. Acaso nunca pueda recobrar aquel entusiasmo y aquella íntima persuasión de saber que realizaba una obra útil para la integración cultural de mi país" (Martínez, 1955a, p. 6).
} 
como intelectual e servidor público. Já no começo dos anos de 1950 trabalhou na campanha de Rui Cortines, presidente da nação entre 1952 e 1958, e, em seguida, na de seu conterrâneo, o romancista Agustín Yáñez para o governo do estado de Jalisco (1953-1959) ${ }^{19}$. Foi ainda deputado federal por Jalisco em dois mandatos, 1958-1961 e 1982-1985.

Essa fase inicial (décadas de 1940 e 50) de acumulação de capital simbólico, na qual Martínez combinou a atividade universitária e política, coincidiu com seu primeiro casamento (1944-1950), com Amalia Hernández Navarro (1917-2000), que viria a ser uma bailarina e coreógrafa célebre, fundadora do Ballet Folclórico de México (1952). Ela era filha de Lamberto Hernández, militar, empresário e político ${ }^{20}$ proeminente e de Amalia Navarro, cuja sobrinha (filha de sua irmã Esperanza Garro), a escritora Elena Garro, foi a primeira mulher de Octávio Paz. Os dois casamentos, o de Octavio Paz com Elena Garro em 1937 e o de sua prima Amalia com José Luis Martínez em 1944 foram celebrados na casa dos pais de Amalia Hernandez. Essa aliança matrimonial propiciou a Martínez um canal de acesso às elites políticas e culturais da Cidade do México e favoreceu o arranque profissional de ambos na segunda metade da década de $1940^{21}$. Seu se-

\footnotetext{
${ }^{19}$ Em suas memórias, o crítico Emmanuel Carballo se refere a uma carta enviada a ele por Alí Chumacero naquele momento: "de José Luis [Martínez] no esperes, por ahora, un texto limpio y a máquina. Está más falto de tiempo que yo. Colabora mañana tarde y noche en los preámbulos de la campaña de Yáñez, y a hurtadillas escribe su sección en 'México en la Cultura'" (Carballo, 2004, p.238).

${ }^{20}$ Lamberto era vinculado ao caudilho militar Saturnino Cedillo, foi senador da república pelo distrito de San Luis de Potosí e, depois, Regente del Departamento del Distrito Federal (que corresponde ao cargo de prefeito no Brasil) entre 1930 e 1931.

${ }^{21}$ De acordo com Pierre Bourdieu, a análise sociológica das alianças matrimoniais, longe do anedotário, é fundamental para a reconstrução das trajetórias dos agentes, uma vez que o casamento altera o conjunto de propriedades sociais de cada um dos cônjuges, afetando o sentido das trajetórias, a estrutura de possibilidades (profissionais, intelectuais, artísticas etc.) e as tomadas de posição. Vale citar: "é difícil caracterizar um indivíduo sem levar em conta todas as propriedades que sobrevém a cada um dos cônjuges - e não apenas às mulheres por mediação do outro, um nome [...] bens, renda, relações e status social" (Bourdieu, 1998, p.123). Para uma análise atenta a tais problemas, enfocando a trajetória de Durkheim, com o título "Le beau mariage d'Emile Durkheim", ver Charle (1984).
} 
gundo casamento escapa completamente dos possíveis condicionantes sociais envolvidos no primeiro. A húngara Lydia Baracs, com quem se casou em 1954, era uma outsider em relação aos círculos sociais prestigiosos da Cidade do México, mas a parceria entre ambos lastreou toda carreira pública posterior de José Luis Martínez.

\section{Projeto intelectual}

Apesar de seu vínculo profissional com a universidade não ter sido regular, há relação direta entre a atividade universitária que desempenhou no período, sobretudo na FFyL da UNAM mas, também, no Colégio do México ${ }^{22}$, e o tipo de trabalho intelectual que produziu (ver acima a progressão de seu trabalho como professor e pesquisador). Atrelada a essa atividade universitária, sua produção no período se unifica pela ambição de reconstituir sistematicamente a formação da literatura mexicana e se materializa nos livros La técnica en literatura. Introducción (1943), Las letras patrias. De la época de Independencia a nuestros días (1946), Literatura mexicana, Siglo XX (1949), La emancipación literaria de México y lo mexicano (1955), Problemas Literarios (1955), La expresión nacional. Letras mexicanas del siglo XIX (1955), De la naturaleza y carácter de la literatura mexicana (1960). O conjunto de trabalhos expressa o notável investimento intelectual do crítico no período, que resultou na publicação de aproximadamente um livro a cada dois $\operatorname{anos}^{23}$. A respeito de seu eixo

\footnotetext{
${ }^{22}$ De seu vínculo com o Colégio do México, resultou o opúsculo El concepto de la muerte en la poesía española (1942). Nesse período, iniciou, também, o trabalho de compilação de textos literários, vertente à qual se dedicaria persistentemente, com a publicação de Poesía romántica (com Alí Chumacero, 1941), Cronistas e historiadores de la conquista de México: el ciclo de Hernán Cortés (com Ramón Iglesia, 1942), Literatura indígena moderna (com Ermilo Abreu Gómez, 1942).

${ }^{23} \mathrm{O}$ investimento acadêmico de Martínez no período pode ser avaliado, também, pela expectativa (abandonada) de estudar teoria literária na Inglaterra, de obter o doutorado, e por seu trabalho como orientador de mestrado, que realizou mesmo sem ter pós-graduação (Martínez Baracs, 2017, p. 14).
} 
temático, devemos notar que, até então, a história da literatura mexicana era pouco cultivada no país ${ }^{24}$ e praticada por polígrafos, sendo seus antecedentes mais conhecidos a Historia de la literatura mexicana (1928), de Carlos González Peña ${ }^{25}$, Historia de la literatura mexicana (1928) e Letras mexicanas en el siglo XIX (1944), de Julio Jiménez Rueda, e Cultura Mexicana: Aspectos Literarios, de Francisco Monterde ${ }^{26}$, e que Martínez alçaria o gênero a outro patamar na tradição intelectual mexicana. Vale a pena mencionar, nessa direção, o esquema das gerações de escritores que Martínez idealizou e que seria quase unanimemente incorporada na autocompreensão que os mexicanos têm de seu passado literário ${ }^{27}$.

A respeito, devemos recuperar um texto publicado na revista El Hijo Pródigo, em 1946, que seria incluído em Problemas Literarios (1955b), com

\footnotetext{
${ }^{24}$ Comparativamente, no México, o gênero da história literária nacional não gozou de muito prestígio nem de uma tradição alentada, ao contrário do Brasil e da Argentina, países em que foi cultivado desde o final do século XIX e muito valorizado (Jackson e Blanco, 2014). Levando em conta a correlação entre tais "histórias literárias" e os processos de construção de identidades nacionais, valeria a pena investigar por que o gênero não teve a mesma força no caso mexicano, sobrepujado por outras formas de produção cultural, como a pintura (o muralismo), a arqueologia, a antropologia e a história, que cumpriram papel decisivo na construção simbólica da nação após a revolução (Hennessy, 1991).

${ }^{25} \mathrm{Em}$ "Panorama de la literatura contemporánea", texto principal de Literatura Mexicana Siglo XX, Martínez qualifica a Historia de Peña como a que "dio cuerpo a las contribuciones parciales existentes y realizó el más articulado y completo manual que poseemos sobre el desarrollo de nuestras letras" (p.25).

${ }^{26}$ As carreiras desses três escritores seguiram o padrão típico da combinação entre atividade acadêmica e serviço público. Todos cultivaram distintos gêneros literários (poesia, ensaio, teatro, romance, conto) antes de experimentarem a história literária. Julio Jimenez Rueda e Francisco Monterde foram professores de Martínez. Monterde inaugurou a Cadeira de Literatura Mexicana na UNAM.

${ }^{27}$ Vale citar dois trechos da avaliação feita pelo escritor José Emílio Pacheco sobre o projeto intelectual de Martínez: "[...] él ha contribuído como pocos a establecer una tradición literaria nacional, a organizar la multitud de autores y de libros en un corpus reconocible como literatura mexicana" (Pacheco, 2010, p.7). "Al llegar a sus treinta años en 1948 José Luis Martínez ya era el autor de El concepto de muerte en la poesía española del siglo XV, La técnica en literatura, Las letras patrias, un panorama de la época de la independencia a 1946 al que debemos una organización generacional que seguimos usando como si hubiera aparecido por sí misma..." (Pacheco, 2010, p.10).
} 
o título Problemas de la historia literaria, no qual José Luis Martínez definira uma perspectiva analítica com matiz sociológico para a consecução de uma história da literatura mexicana. Tal perspectiva teria como princípio a ideia de que a literatura se faz a partir de grupos, diferenciados em gerações (definidas por certa ideologia compartilhada) e promoções (formadas por grupos heterogêneos). A reconstrução da sucessão das gerações constituiria, como veremos, o eixo de seu esquema, chancelado por Alfonso Reyes em carta enviada a Martínez e publicada no mesmo livro ${ }^{28}$.

Outro texto, Situación de la literatura mexicana contemporánea, incluído no mesmo livro, permite avaliar o posicionamento e as apostas de José Luis Martínez no espaço literário mexicano do final da década de 1940. O artigo derivou de um convite que recebeu em 1948 para colaborar com a revista México en el Arte, editada pelo Instituto Nacional de Belas Artes. José Luis Martínez preparou um trabalho que avaliava negativamente a situação da literatura mexicana entre as décadas de 1930 e 1940. Sua proposta foi recusada pelo comitê da revista e, em função disso, ele enviou o trabalho ao historiador Jesus Silva Herzog, a quem conhecia e que era, então, editor de Cuadernos Americanos, que decidiu publicá-lo. Vale lembrar que, um ano antes, a revista havia publicado um ensaio crítico de Daniel Cosío Villegas sobre os rumos que havia tomado a revolução mexicana e que Silva Herzog faria o mesmo, também em 1948.

No artigo, Martínez contrariava as expectativas dos editores de México en el Arte ao enunciar uma crítica contundente ao nacionalismo cultural que, para o autor, orientava a produção literária da década que examinava (final da década de 1930 / final da década de 1940), com consequências empobrecedoras. Se seu diagnóstico se alinhava ao posicionamento

${ }^{28}$ Vale citar uma breve passagem: "Su pequeño ensayo [...] me parece un programa para desarrollos futuros, una verdadera hipótesis de trabajo" (Reyes apud Martínez, 1955b, p. 59). Alfonso Reyes publicou a carta em De viva voz 1920-1947 (1949), José Luis Martínez a republicou no livro citado. 
político de Cosío Villegas e Silva Herzog, expressando os primeiros sinais de descontentamento de uma fração da comunidade intelectual com os rumos da revolução, pode ser entendido, também, como uma tomada de posição que tinha como pressuposto implícito a pretensão dos críticos (e dele mesmo, nessa posição) de se constituírem em árbitros da atividade literária, favorecidos pela neutralidade que a especialização garantiria. O texto suscitou reações duras, descritas pelo próprio Martínez no livro Problemas literarios, de 1955, no qual o texto foi incluído posteriormente, produzindo efeitos ambíguos para o seu autor. A polêmica certamente o pôs em evidência, mas não deve ter sido fácil para o jovem de trinta anos enfrentá-la.

De qualquer modo, o projeto mais ambicioso de Martínez visava reconstituir o processo formativo da história literária nacional. Devemos atentar ao fato de que o primeiro trabalho realizado nessa direção, Las letras patrias. De la época de Independencia a nuestros días (1946), resultou de uma encomenda oficial de Jaime Torres Bodet, que estava à frente da Secretaria de Educação Pública, de quem Martínez era secretário particular. O projeto imaginado por ambos, e que teve como resultado o livro Mexico y la Cultura, tinha como objetivo coroar a gestão de Bodet, oferecendo um mapa das grandes realizações da cultura mexicana. O convidado para escrever o capítulo sobre literatura foi Alfonso Reyes, que solicitou a colaboração do próprio Martínez, que escreveu sobre o século XIX ${ }^{29}$. O episódio revela, uma vez mais, a centralidade do Estado na produção cultural e na articulação das instâncias política, literária e acadêmica ${ }^{30}$, envolvidas na origem desse que foi o texto seminal do projeto intelectual do jovem crítico.

O núcleo de seu argumento sobre a formação da literatura mexicana pode ser apreendido em dois textos que reconstituem tal processo nos

\footnotetext{
${ }^{29}$ Para uma narrativa detalhada dessa encomenda, ver Martínez Baracs (2017), em vias de publicação.

${ }^{30} \mathrm{Na}$ página de rosto de sua colaboração no livro México y la Cultura, José Luis Martínez é apresentado como "Catedrático de la Facultad de Filosofia y Letras".
} 
séculos XIX e XX. O primeiro, México en busca de su expresión, embora publicado na década de 1970 na importante Historia general de México, coordenada por Daniel Cosío Villegas, foi composto a partir dos trabalhos realizados nas décadas de 1940 e 50, mencionados acima. O segundo Panorama de la literatura contemporánea (1910-1949) constitui a parte principal do livro Literatura Mexicana Siglo XX (1949), que teria uma nova versão ligeiramente transformada, com o título La literatura, publicada no livro México: cincuenta años de revolución (FCE/1960-1962).

No quadro traçado por Martínez a respeito do século XIX, na verdade dos cem anos compreendidos entre 1810 (a independência) e 1910 (a revolução), os marcadores políticos mobilizados se justificam pela hipótese geral de que a literatura teria se constituído nesse século, no México, a reboque da política e que sua polarização inicial entre os escritores identificados como conservadores ou liberais seria uma evidência de sua condição heterônoma. A superação desse entrave seria lenta e descontínua durante a primeira metade do século e começaria a avançar em ritmo regular durante a "concórdia nacionalista" (1867-1889), liderada pelo escritor que figura, em seu esquema, no centro do esforço coletivo de construir as bases de uma literatura nacional, Ignacio Manuel Altamirano. Esse avanço teria sido possível em função da relativa estabilização política em curso, que teria favorecido o adensamento de instituições culturais públicas e iniciativas privadas, sobretudo, associações e revistas. Finalmente, em função do adensamento cultural ocorrido e do declínio do nacionalismo literário, o modernismo emergiria, no final do século, para impor-se como tônica dominante dessa última fase, já no interior do porfiriato.

A transição para o século XX é discutida no início de seu Panorama de la literatura contemporânea (1910-1949) [1949] e seria marcada, apesar da revolução, pelo (suposto) afastamento progressivo da atividade literária em relação à política e por seu desenvolvimento mais consistente, o que se comprovaria a partir de sua argumentação pelo volume da produção literária coligida, em relação ao século XIX. O marco literário 
dessa reorientação seria a emergência do Ateneu da Juventude, que teria protagonizado, para o autor, uma verdadeira "revolução cultural" (p. 18), ao fixar novo "espírito" para a intelectualidade emergente, que Pedro Henríquez Ureña teria definido como "filosófico" (p. 20) e, de fato, as figuras mais expressivas do grupo - (além de Henríquez Ureña) Alfonso Reyes, Antonio Caso e José Vasconcelos - praticaram, sobretudo, gêneros eruditos, como estudos literários, históricos etc. A geração de 1915 seria, para Martínez, uma derivação direta da geração do Ateneu, mas seus membros teriam se especializado mais, como Antonio Castro Leal (crítica) e Alfonso Caso (arqueologia), ou transitado a posições destacadas no sistema político, como Manuel Gomez Morin ou Vicente Lombardo Toledano. As próximas gerações destacadas pelo crítico seriam as das revistas Contemporáneos (1928-1931), Taller (1938-1941), e Tierra Nueva (1940-42). Nesse esquema interpretativo, tais grupos/gerações constituiriam uma espécie de eixo ordenador da literatura mexicana da primeira metade do século $X X^{31}$, que teria logrado um desenvolvimento sem precedentes, apesar do aparente declínio que Martínez entrevia na década de 1940, que parecia terminar sem grandes promessas, conforme avaliação que havia feito no texto comentado acima. A versão posterior do texto, com o título La literatura, publicada no livro México: cincuenta años de revolución (FCE/1960-1962), no entanto, apresenta conclusão distinta, mais otimista ${ }^{32}$, refletindo o surgimento da nova geração literária (a sua própria), formada por, entre outros, Juan Rulfo, Juan José Arrreola, Alí

\footnotetext{
${ }^{31}$ Se o texto se estriba nessa hipótese, esta não esgota seu andamento, uma vez que algumas das melhores expressões literárias do período proviriam de escritores relativamente afastados desses grupos principais, como teria ocorrido com os romancistas da revolução.

${ }^{32}$ Vale citar: "Considerada en su conjunto, la literatura mexicana reciente da la impresión de encontrarse en uno de los períodos más activos y fértiles en la historia de nuestras letras. Herederas del lento y complejo esfuerzo que vino gestándose desde la generación de 1910, las generaciones y promociones actuales parecen destinadas a llevar a cabo, al fin, el salto que libre a la literatura mexicana del provincianismo, del aislacionismo que no ha había podido superar hasta ahora -salvo contadas excepciones- para existir y circular en un clima universal" (Martínez, 1961, p. 368)
} 
Chumacero e Carlos Fuentes (que, embora nascido dez anos depois dos outros, emergiu na cena literária ao mesmo tempo, na década de 1950), mas, sobretudo, o reposicionamento de Martínez no espaços literário e político em função de seu ingresso na Academia Mexicana de la Lengua, com o apoio direto de Alfonso Reyes, e de sua eleição como deputado federal pelo PRI, patrocinado por Agustín Yáñez, ambos em 1958; que o levaram a rever e moderar suas avaliações anteriores.

O cânone ordenado por Martínez traduziu, de certo modo, as relações entre escritores e críticos em seu país, marcadas pela dominação dos primeiros sobre os segundos (e a sua própria trajetória intelectual no interior desse campo de forças). José Luis Martinez teve como padrinhos intelectuais e políticos alguns dos principais escritores do país. Foi o caso, como vimos, de Alfonso Reyes, Jaime Torres Bodet e Agustín Yánez. Tais relações expressam o maior grau de integração entre "cultura universitária" e "cultura literária" no México, comparado com o Brasil e a Argentina. Essa propriedade do campo pode ser flagrada tanto nas avaliações sobre o cânone literário mexicano, que José Luis Martínez fixou em Literatura Mexicana Siglo XX (e em outros textos), por meio das quais o crítico entronizou esses três escritores, como no papel de "curador" (Said, 1999) de suas obras que desempenhou, organizando antologias e publicando volumes de correspondência. Essas relações intelectuais podem ser compreendidas como contraprestações às oportunidades de trabalho propiciadas a ele por esses escritores (ao mesmo tempo em que escrevia seus textos) ${ }^{33}$ e em função da amizade que manteve com eles ${ }^{34}$.

\footnotetext{
${ }^{33}$ Foi secretário de uma das instituições do establishment cultural mexicano, El Colégio Nacional, indicado por Alfonso Reyes, um dos fundadores dessa instituição, entre 1947 e 1951. Foi secretário de Torres Bodet, na Secretária de Educação Pública entre 1943 e 1946, de quem havia sido aluno na FFyL/UNAM. Trabalhou na campanha política de Agustín Yánez para o governo de Jalisco em 1952.

${ }^{34}$ Alfonso Reyes foi testemunha do segundo casamento, com Lidia Baracs, em 1954 (Martínez, 1996, p.10). Agustín Yáñez e sua mulher, Olivia Yáñez foram padrinhos da filha de José Luis Martínez com Lidia Baracs, Andrea Guadalupe (idem, p.13).
} 


\section{Comparação}

Arrisquemos agora uma comparação entre os processos de enraizamento universitário da crítica literária no México, no Brasil e na Argenti$\mathrm{na}^{35}$, tomando como referência as trajetórias de José Luis Martínez, Antonio Candido e Adolfo Prieto, agentes decisivos desses processos nesses países. Apesar das diferenças marcadas, a comparação é possível em função da centralidade obtida pelas universidades na produção cultural, a partir de meados do século XX nesses países, que afetou o jogo de forças nos campos intelectual e literário. Os críticos universitários reivindicaram o papel de árbitros, de principais ordenadores do cânone literário, em relação às tradições estabelecidas pelos próprios escritores e/ou por críticos não especializados. A temporalidade quase simultânea desse movimento, concentrado em torno de 1950, também sugere a inscrição dos casos num quadro mais amplo que pode ser reconhecido na escala da América Latina.

Mais especificamente, as bases institucionais principais desse movimento foram as faculdades de filosofia e letras, e a força relativa que conquistaram (cultura universitária versus cultura literária), somada a outros fatores como o recrutamento social dos alunos e professores, explicam em boa medida as diferenças entre os casos, condicionadas também pelas lógicas e temporalidades específicas das evoluções das tradições literárias nacionais e pelas relações estabelecidas entre críticos e escritores.

A experiência da Argentina é ótima para dar concretude a essas considerações gerais. A criação da Faculdade de Filosofia e Letras da UBA, em 1896, foi parte do processo mais amplo das políticas educacionais que visaram a expansão do sistema educacional e superior, especificamente. Em seus cursos, ingressaram massivamente imigrantes europeus e seus descendentes ao longo da primeira metade do século XX, de modo que a

\footnotetext{
${ }^{35}$ Fizemos em texto recente (2016) uma comparação análoga sobre o desenvolvimento da sociologia nos três países.
} 
FFyL da UBA foi, na Argentina, o berço principal das sucessivas gerações de críticos literários. Tais aspectos ajudam a entender por que, nesse caso, as relações entre os escritores (majoritariamente recrutados nas famílias tradicionais criollas) e os críticos, nesse período, foram pautadas principalmente pelo confronto. Atenuado no contexto peronista (1946-1955) que aproximou as diversas frações intelectualizadas (ensaístas, sociólogos, escritores, críticos etc.), alinhadas contra o regime, os anos posteriores à queda de Perón foram caracterizados pela emergência de novas gerações de críticos universitários que desafiaram os escritores mais prestigiosos do país, como Jorge Luis Borges, Eduardo Mallea, Victoria Ocampo, Adolfo Bioy Casares, nucleados na revista Sur. Nesse contexto, surgiu a revista Contorno (1953-1959), que reuniu um grupo seleto de jovens críticos formados na FFyL, integrado, entre outros, por Ismael e David Viñas, Juan José Sebreli, Adolfo Prieto, León Rozitchner, Oscar Masotta e Noé Jitrik. A reabilitação literária, por parte do grupo, do escritor plebeu Roberto Arlt, um descendente de imigrantes, desafiando o cânone estabelecido, explicitou a existência de uma configuração que posicionou críticos (cultura universitária) e escritores (cultura literária) em polos opostos do campo literário.

Filho de um imigrante espanhol dedicado ao comércio, Adolfo Prieto (1928-2016) nasceu na cidade de San Juan, no estado de mesmo nome. Mudou-se para Buenos Aires no ano de 1946, desprovido de capital cultural, e ingressou no curso de letras da FFyL da UBA. Alguns anos depois, integraria o grupo de Contorno. A opção pela carreira acadêmica propriamente dita foi abraçada, sobretudo, por ele, possivelmente condicionada por sua origem provinciana que contrastava com a da maioria dos membros do grupo. Prieto terminou a graduação em letras no ano de 1951 e obteve o título de doutor em 1953, num momento em que realizar a pós-graduação era incomum. Borges y la nueva generación (1954) foi seu primeiro livro, publicado quando tinha apenas 26 anos. 
Nele, atacou a figura dominante da literatura argentina e a mais conhecida no exterior. O gesto ousado de Adolfo Prieto o inseriu abruptamente na cena literária argentina e reivindicou para os críticos uma posição mais autônoma. Em 1959 ingressou como professor na Universidade Nacional do Litoral (UNL), em Rosario, na qual dedicou-se intensamente à pesquisa, à docência e à gestão acadêmica. Até 1966 (quando se demitiu após a intervenção nas universidades em seguida ao golpe de Onganía), publicou a maior parte de seus trabalhos.

O itinerário descrito revela o investimento realizado por Adolfo Prieto entre os anos de 1950 e 1960, período em que concretizou sua aliança matrimonial (1957) com Reymunda Estela Jarma, também de origem provinciana e sua colega no curso de letras. Nesse período, ele formou e liderou um grupo destacado de pesquisadoras (entre as quais, Noemi Ulla, Josefina Ludmer e Gladys Onega); dirigiu, na Universidade Nacional do Litoral, a Faculdade de Filosofia e Letras, o Instituto de Letras e o Boletín de Literatura Hispánica; publicou uma tese de doutorado e dez livros, Borges y la nueva generación (1954); Sociología del público argentino (1956); Proyección del rosismo en la literatura argentina (1959); La literatura autobiográfica argentina (1962); Encuesta: la crítica literária en la Argentina (1963); Antología de Boedo y Florida (1964); El periódico Martín Fierro (1968); Literatura y subdesarrollo (1968); Diccionario básico de literatura argentina (1968); Estudios de literatura argentina (1969).

Já fora da universidade, Prieto dirigiu uma das principais empreitadas culturais desse período, Capítulo: La historia de la literatura argentina (1967/1968), editada pelo Centro Editor da América Latina, uma história social da literatura argentina, cujas hipóteses orientariam o desenvolvimento posterior da crítica literária na Argentina. Pouco depois, após o início da ditadura militar de 1976, Prieto emigrou aos Estados Unidos, onde lecionou por cerca de quinze anos. A publicação e a recepção muito favorável 
de El discurso criollista en la formación de la Argentina moderna, no ano de 1988 interromperia esse período de relativo isolamento intelectual.

As condições que envolveram a carreira de Antonio Candido, em relação às de Martínez e Prieto, foram certamente mais favoráveis, inicialmente, em função das vantagens derivadas de sua origem social elevada. Nasceu em 1918, seu pai, um médico, e sua mãe descendiam de famílias tradicionais de Minas Gerais e do Rio de Janeiro e tiveram acesso privilegiado à cultura própria dos círculos intelectualizados das elites de tais estados. Em função de tais circunstâncias, Antonio Candido obteve educação elevada desde criança. Sua iniciação literária foi precoce, mas adquiriu formação intelectual sistemática, principalmente, no curso de ciências sociais da FFCL-USP (1939-1941), em especial sob a batuta de professores da missão francesa, como o filósofo Jean Maugüé e o sociólogo Roger Bastide (Pontes, 1998; Jackson, 2002). Em 1942, assumiu o cargo de primeiro assistente de Fernando de Azevedo, na Cadeira de Sociologia II, na qual permaneceu até 1958. Entre 1941 e 1944, participou do grupo de estudantes da FFCL/USP que editou a revista Clima, publicação que teria notável repercussão no cenário cultural paulista e definiria as direções profissionais não apenas de Antonio Candido, mas também dos críticos de teatro Décio de Almeida Prado e de cinema Paulo Emílio Salles Gomes (Pontes, 1998). Também fazia parte do grupo Gilda de Moraes Rocha (posteriormente Gilda Rocha de Mello e Souza), oriunda de família paulista tradicional, com quem se casou. Em 1942, projetado pelo impacto dos textos que publicou em Clima, passou a escrever semanalmente na Folha da Manhã, ingressando no círculo prestigioso dos críticos literários que escreviam para os grandes jornais de São Paulo e do Rio de Janeiro, na chamada "crítica de rodapé" (Bolle, 1979; Sussekind, 1993).

Os anos em que escreveu semanalmente para os jornais Folha da Manhã (entre janeiro de 1943 e janeiro de 1945) e Diário de São Paulo 
(entre setembro de 1945 e fevereiro de 1947) foram decisivos para afirmar sua reputação como crítico literário. Ao mesmo tempo, ele lecionou sociologia na Universidade de São Paulo, trilhando caminhos paralelos. Na década de 1950 preparou aqueles que seriam considerados seus dois principais trabalhos: a tese de doutorado em sociologia, Os parceiros do Rio Bonito, defendida em 1954 e publicada como livro em 1964, e A formação da literatura brasileira, publicado em 1959. Neste livro, integrou os pontos de vista sociológico e estético para entender o processo de formação da literatura brasileira como sistema (autor-obra-público) e sua autonomização em relação à literatura portuguesa, movimento que ocorreria entre os séculos XVIII e XIX.

Após ensinar letras por três anos na Faculdade de Filosofia de Assis, assumiu em 1961 a Cadeira de Teoria Literária e Literatura Comparada da FFCL-USP. Vencido o dilema profissional, Antonio Candido assumiu explicitamente a liderança de um programa coletivo de pesquisas, que the permitiu ampliar o impacto de sua obra nas décadas seguintes, nas quais sua carreira transcorreria sem interrupções no interior da universidade. Com a ajuda de seus discípulos (entre os quais Roberto Schwarz, Walnice Nogueira Galvão e Davi Arrigucci Jr.) ele fixaria um novo e mais exigente padrão de trabalho intelectual na crítica literária brasileira. Nessa direção, a Formação constituiu-se como o núcleo das formulações teóricas e interpretativas que iriam nortear seus principais trabalhos posteriores - Tese e antítese (1964), Literatura e sociedade (1965), Vários escritos (1970), A educação pela noite (1987) e O discurso e a cidade (1993) - e os de seus discípulos, legitimando a crítica literária como uma especialidade no interior das ciências humanas.

No México, os críticos especializados que tentaram se impor desde a década de 1940 também tiveram como base principal a universidade e a Faculdade de Filosofia e Letras, na qual os professores exilados 
espanhóis introduziram novos padrões de análise literária, baseados em pesquisa sistemática. Atentemos, entretanto, para as diferenças principais entre os casos, avaliando, inicialmente, as relações dos críticos com os escritores. Nesse caso, elas foram pautadas antes pela aliança do que pela disputa. Isso se explica pelo maior grau de integração das distintas frações das elites intelectuais e artísticas na Cidade do México, condicionada pela afinidade das origens sociais, pela formação educacional comum, pelos espaços de sociabilidade compartilhados.

Já no Brasil, em São Paulo especificamente, se os críticos e escritores eram recrutados mais ou menos nos mesmos grupos sociais (Jackson; Blanco, 2014), as oligarquias em declínio (Miceli, 2001), os grupos estavam relativamente mais afastados em função da maior diferenciação que havia entre essas atividades, sobretudo, após a criação das universidades na década de 1930 e da USP, em particular, que rapidamente se tornou fonte de um novo tipo de autoridade intelectual. Isso explica a ocorrência de polêmicas como a que envolveu o crítico Antonio Candido e o escritor modernista Oswald de Andrade (Pontes, 1998). A afinidade social entre críticos e escritores, contudo, estaria por trás de relações de aliança como a que se explicitou no patrocínio intelectual de Mário de Andrade (que era primo em primeiro grau da mãe de Gilda de Mello Souza, a esposa de Antonio Candido) à revista Clima, plataforma de lançamento desse grupo de críticos universitários.

Na Argentina, como dissemos acima, onde a origem social e a formação educacional de críticos (imigrantes e descendentes de imigrantes) e escritores (majoritariamente descendentes de famílias criollas) eram distintas, os primeiros formados na FFYL/UBA e os segundos educados no interior da família, prevaleceu o confronto entre uns e outros, emblematicamente expressado no livro Borges y la nueva generación (1954). O padrão conflitoso de relação entre escritores e críticos implicou, nesse 
último caso, o questionamento do cânone literário anteriormente estabelecido, enquanto no México, José Luis Martínez, e no Brasil, Antonio Candido (embora tenham inovado do ponto de vista analítico a reconstrução da história literária de seus respectivos países), tenderam a reafirmá-lo (confirmando Alfonso Reyes e Machado de Assis como os maiores escritores de cada tradição).

Tomemos agora como ponto de comparação suas trajetórias profissionais. Embora os projetos intelectuais dos três críticos tenham como condicionante principal a inserção na universidade, há diferenças importantes a serem notadas. Os três foram professores universitários, mas Antonio Candido e Adolfo Prieto se dedicaram por toda vida, integralmente, a essa ocupação, enquanto José Luis Martínez foi professor universitário apenas nas décadas de 1940 e 1950 e, mesmo assim, dividido entre a docência e o serviço público. A compreensão dessa diferença em relação às carreiras deve levar em conta as estruturas de possibilidades vigentes em cada caso. As organizações acadêmicas no Brasil e na Argentina (principalmente na USP e na UBA) permitiam maiores possibilidades de dedicação em tempo integral à docência e à pesquisa ${ }^{36}$ e os professores não eram comumente cooptados pelo Estado para o serviço público. No México, ao contrário, a carreira de professor universitário estava atrelada ao serviço público, o que expressava as relações de dependência do campo intelectual ao campo político.

Os trabalhos de Roderic Camp demonstraram o alto grau de interdependência entre as elites intelectual e política no México, recrutadas ambas nas classes médias urbanas, com formação educacional compartilhada, transitando da Escola Nacional Preparatória à Universidade Nacional e, portanto, a dependência dos intelectuais em relação ao Estado,

36 No México, na década de 1960, a quase totalidade (97\%) dos professores trabalhava em regime de dedicação parcial (Camp, 1983, p.19). 
cuja face mais visível foi a cooptação política ${ }^{37}$. Devemos evitar, contudo, a avaliação enviesada (feita a partir dos parâmetros de legitimação característicos das experiências brasileira e argentina) que levaria a subestimar o significado (e o peso) da carreira universitária no México. Neste país, o trânsito entre as ocupações era muito frequente e, ao contrário de ser reprovado, era considerado um sinal de reconhecimento. Nesse sentido, a designação de um professor/pesquisador para um alto cargo político/ diplomático comprovava a consagração do mesmo, apesar de implicar eventualmente (como ocorreu com Martínez) a descontinuidade de sua carreira acadêmica.

De qualquer modo, o único entre os três agentes aqui comparados que dispôs de uma carreira contínua, no interior da mesma instituição e dentro de seu país, foi Antonio Candido e essa condição foi decisiva tanto à regularidade de sua produção (e de seu grupo), como à sua consagração cada vez mais inconteste. Por razões distintas, recordemos, as carreiras de Prieto e Martínez foram descontinuadas, a primeira pelas intervenções ocorridas nas universidades argentinas durante o ciclo militar e a segunda pela opção de Martínez pela carreira funcional. Nos dois casos, tais interrupções (Prieto seguiu a carreira nos Estados Unidos) implicaram queda de produtividade e afetaram as possibilidades de consagração futura (mais estritamente acadêmica) de suas obras.

Um notável ponto de aproximação relaciona-se com o fato de as plataformas de lançamento dos três críticos no campo intelectual terem sido revistas universitárias, Clima, Contorno e Tierra Nueva, que constituíram, ao mesmo tempo, grupos culturais fortemente integrados. A diferen-

\footnotetext{
${ }^{37}$ Em termos analíticos, as relações entre campo político e campo intelectual variam em função da distância social entre esses universos (quanto menor a distância, maior a dependência), que pode ser medida pela frequência dos cruzamentos inter e intrageracionais (de um meio a outro), ou por indicadores como origem social, formação educacional, círculos de sociabilidade e alianças matrimoniais (Bourdieu, 1995, p.327).
} 
ça fundamental entre os grupos reside na tomada de posição contestatória (e politizada) que os contornistas encamparam em relação aos escritores estabelecidos, o grupo de Sur, e na reivindicação, já mencionada, de um contra cânone literário centralizado na figura de Roberto Arlt. Tal atitude seria condicionada pela origem social e geográfica de seus membros, em geral descendentes de imigrantes, alguns originados da província, outros das frações baixas da classe média urbana e judeus (Katra, 1988). A renovação introduzida pelo grupo Clima (Pontes, 1999), todos com origem elevada apesar das diferenças de grau, consistiu na promoção de uma nova dicção para a crítica literária e cultural, que teve lastro na experiência universitária compartilhada, a qual se contrapunha à tradição da "crítica de rodapé", designada como "impressionista". Na mesma direção, o grupo de Tierra Nueva, unificado pela origem provinciana comum (com a exceção de Leopoldo Zea), propôs uma perspectiva mais rigorosa aos estudos literários, também apoiada na socialização universitária.

Por fim, o balanço das diferenças e semelhanças entre as três trajetórias consideradas (e seus respectivos contextos) sugere que os críticos literários alcançaram, nos três países, na década de 1950, uma posição de maior autonomia em relação aos escritores, condicionada por sua inserção acadêmica. Nessa direção, a universidade foi a fonte principal de legitimação de suas pretensões, sobretudo, a de se constituírem como árbitros da produção literária, objetivo que atingiram desigualmente em função da estrutura de possibilidades vigente em cada caso.

Luiz Carlos Jackson é Livre Docente em Sociologia e professor associado do Departamento de Sociologia da FFLCH-USP. \ljackson@usp.br.

Alejandro Blanco é sociólogo e Doutor em História (UBA), professor do Departamento de Ciência Sociais da Universidade Nacional de Quilmes (UNQ).

Mablanco@unq.edu.ar. 


\section{Bibliografia}

1. ARRUDA, Maria Arminda do N. Metrópole e cultura. São Paulo: EDUSC, 2001.

2. BOLLE, Adélia Bezerra de M. A obra crítica de Álvaro Lins e sua função histórica. Petrópolis: Vozes, 1979.

3. BOURDIEU, Pierre. Las reglas del arte. Barcelona: Anagrama, 1995.

4. BOURDIEU, Pierre. La distinción. Madrid: Taurus, 1998.

5. CAMP, Roderic. La formación de un gobernante. La socialización de los líderes políticos en el México post-revolucionario. Cidade do México: Fondo de Cultura Económica, 1981.

6. CAMP, Roderic. Los líderes políticos de México. Su educación y reclutamiento. Cidade do México: Fondo de Cultura Económica, 1983.

7. CAMP, Roderic. Los intelectuales y el Estado en el México del siglo XX. Cidade do México: Fondo de Cultura Económica, 1988.

8. CARBALLO, Emmanuel. Entrevista a José Luis Martínez. Revista Iberoamericana, v. LV, n. 148/149, p. 665-74, 1989.

10. CARBALLO, Emmanuel. Ya nada es igual. Memorias (1929-1953). Cidade do México: Fondo de Cultura Económica, 2004.

11. CASTAÑON, Adolfo. Falleció José Luis Martínez, "curador de las letras mexicanas". La Jornada, 21 mar. 2007, Cidade do México, 2007.

12. CHARLE, Christophe. Le beau mariage d'Emile Durkheim, Actes de la Recherche en Sciences Sociales, v. 55, p. 45-59, 1984.

13. COSER, Lewis. Los diferentes roles de los intelectuales en Francia, Inglaterra y Estados Unidos en la actualidad. In: MARSAL, Juan. El intelectual latinoamericano. Buenos Aires: Editorial del Instituto, 1967.

14. COSER, Lewis. Hombres de ideas. El punto de vista de un sociólogo. Cidade do México: Fondo de Cultura Económica, 1968.

15. FRANCO BAGNOUS, María de Lourdes. El exilio español en las revistas de Octavio G. Barreda: Letras de México y el Hijo pródigo. Cuadernos Iberamericanos, n. 1, p. 61-74, 2015.

16. GARCIADIEGO, Javier. (1996). Rudos contra científicos. La Universidad Nacional durante la revolución mexicana. Ciudad de México, El Colegio de México.

17. GARGANIGO, John F.. (1965), "Tierra Nueva: su estética y poética", Revista Iberoamericana, vol. XXXI, n-60 
18. GARRIDO, Felipe (org.). Celebración de José Luis Martínez en sus setenta años. Guadalajara: Universidad de Guadalajara, 1990.

19. GARZA, Gustavo. La urbanización de México en el siglo XX. Cidade do México: El Colegio de México, 2005.

20. HENNESSY, Alistair. The muralists and the revolution. In: CAMP, Roderic; HALE, Charles; ZORAIDA, Josefina (orgs.). Los intelectuales y el poder en México. Cidade do México: Colegio de México, 1991.

21. JACKSON, Luiz. A tradição esquecida - Os parceiros do Rio Bonito e a sociologia de Antonio Candido. Belo Horizonte: Editora UFMG, 2002.

22. JACKSON, Luiz; BLANCO, Alejandro. Sociologia no espelho: ensaístas, cientistas sociais e críticos literários no Brasil e na Argentina. São Paulo: Editora 34, 2014.

23. JACKSON, Luiz; BLANCO, Alejandro. O caudilho da sociología mexicana. Pablo González Casanova e a democracia no México. Tempo Social, v. 28, n. 3, p. 117-43, 2016.

24. KANDELL, Jonathan. La capital. La historia de la ciudad de México. Buenos Aires: Javier Vergara Editor, 1990.

25. KATRA, William H. Contorno. Literary Engagement in Post-Peronist Argentina. Londres: Associated University Press, 1988.

26. KRAUZE, Enrique. Caudillos culturales en la Revolución mexicana. Cidade do México: Siglo XXI, 1976.

27. KRAUZE, Enrique. José Luis Martínez. Letras Libres, 31 ago. 2007. Cidade do México, 2007.

28. LEMPÉRIÈRE, Annick. Le clercs de la nation: intellectuels, Etat et société au Mexique. Paris: L'Harmattan, 1992.

29. LIDA, Clara; MATESANZ, José Antonio. El Colegio de México: una hazaña cultural (1940-1962). Cidade do México: Colegio de México, 1990.

30. LOAEZA, Soledad. Clases medias y política en México. Cidade do México: Colegio de México, 1988.

31. MARTÍNEZ, José Luis. Literatura mexicana. Siglo XX: 1910-1949. Cidade do México: Antigua Librería Robredo, 1949.

32. MARTÍNEZ, José Luis. La emancipación literaria de México. Cidade do México: Antigua Librería Robredo (México y lo mexicano), 1955a.

33. MARTíNEZ, José Luis. Problemas literarios. Cidade do México: Obregón, $1955 b$. 
34. MARTÍNEZ, José Luis. Recuerdo de Lupita. Cidade do México: Ediciones Papeles Privados, 1996.

35. MARTÍNEZ BARACS, Rodrigo. Estudio preliminar. In: MARTÍNEZ BARACS, Rodrigo; DELIRA, Maria Guadalupe Ramirez (orgs.). Alfonso Reyes y José Luis Martínez. Una amistad literaria. Correspondencia (1942-1959). No prelo, 2017.

36. MEYER, Lorenzo. Agenda ciudadana. El espejo de Don Pablo, Reforma, 15 dez. 2005.

37. MICELI, Sergio. Intelectuais à brasileira. São Paulo: Companhia das Letras, 2001.

38. MONSIVÁIS, Carlos. Notas sobre la cultura mexicana en el siglo XX. In: VILLEGAS, Daniel Cosío (org.). Historia General de México, v. 2. Cidade do México: Colegio de México, 1981.

39. PACHECO, José Emilio. Prólogo. In: MARTíNEZ, José Luis. Obra reunida. v. 1, Cidade do México: Universidad Nacional de México, 2010.

40. PONTES, Heloisa. Destinos mistos. São Paulo, Companhia das Letras, 1998. 41. SARLO, Beatriz. Una modernidad periférica. Buenos Aires: Nueva Visión, 1988. 42. SIGAL, Silvia. Intelectuales y poder en la década del sesenta. Buenos Aires: Puntosur, 1991.

43. SUSSEKIND, Flora. Papéis colados. Rio de Janeiro, Editora da UFRJ, 1993.

44. VALERO, Vida; HERRERA, Alejandra. Una conversación con Alí Chumacero. Tema y variaciones de literatura, n. 25, Departamento de Humanidades, UAM$-A, 2005$.

45. VVAA. El exilio español en México, 1939-1982. Cidade do México: Fondo de Cultura Economica, 1982.

46. VVAA. Los refugiados españoles y la cultura mexicana. Cidade do México, Colegio de México, 1999.

47. ZABLUDOVSKY, Gina. La emigración republicana española y el pensamiento alemán en México: la traducción de Economía y sociedad. Revista Mexicana de Ciencias Políticas y Sociales, n. 3, p. 169-88, 2002.

48. ZAID, Gabriel. De los libros al poder. Cidade do México: Editorial Océano de México, 1999.

49. ZAID, Gabriel. José Luis Martínez. Letras libres, 30 set. 1999, Cidade do México, 1999.

Recebido: 28.09.2017

Aceite final: 15.10 .2017

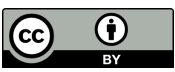

